\title{
Effect of dexamethasone on levels of inflammatory factors and EGF mRNA in rabbits suffering from oral ulcers
}

\author{
Weiliang Wu${ }^{1}$, Jianyong Ruan', Daxu $\mathrm{Li}^{2}$, Hong Tao², Chunni Deng ${ }^{2}$, Rui Wang ${ }^{3}$, \\ Wei Cheng ${ }^{4}$, Zhe Zhang ${ }^{2}$, Le Ren ${ }^{2 *}$ \\ ${ }^{1}$ Department of Oral Implantology, The Affiliated Stomatological Hospital of Fujian Medical University, Fuzhou 350001, Fujian, \\ ${ }^{2}$ Department of Stomatology, The First Affiliated Hospital, Medical School of Xi'an Jiaotong University, Xi'an, Shaanxi 710061, \\ ${ }^{3}$ Department of Aesthetic \& Plastic Craniofacial Surgery, The First Affiliated Hospital, Medical School of Xi'an Jiaotong \\ University, Xi'an, ${ }^{4}$ Department of Head and Neck Oncology, Shaanxi Provincial Tumor Hospital, Xi'an 710061, China
}

*For correspondence: Email: renle007@126.com

Sent for review: 18 September 2020

Revised accepted: 20 January 2021

\begin{abstract}
Purpose: To investigate the therapeutic effect of dexamethasone on rabbits suffering from oral ulcers, and the underlying mechanism(s) of action.

Methods: A rabbit model of oral ulcer was established by applying $40 \%$ glacial acetic acid solution to the oral buccal membranes of the animals. Three groups of rabbits were used. Changes in area of the oral ulcer were recorded after dexamethasone administration. Levels of epidermal growth factor (EGF) were assayed using reverse transcription PCR (RT-PCR), while MDA levels and expression levels of IL6, IL-8 and TNF- $\alpha$ were determined by enzyme-linked immunosorbent assay (ELISA). Local histopathological changes were examined histologically with the aid of hematoxylin and eosin (H \& E) staining.

Results: There were reductions in ulcer areas in group $C$ on the 2nd, 4th and 7th days of dexamethasone administration, when compared with group $B(p<0.05)$. The EGF levels in the buccal mucosa of rabbits in groups $B$ and $C$ were significantly higher than those in group $A(p<0.05)$, while the highest EGF level was in group $C(p<0.05)$. The levels of MDA, IL-6, IL-8, and TNF- $\alpha$ significantly increased in groups $B$ and $C(p<0.05)$. Results from $H \& E$ staining showed lower levels of inflammatory cells in group $C$ than in group $B$, with visible proliferation of fibroblast cells and epithelial cells in group $C$ after dexamethasone administration.

Conclusion: Dexamethasone accelerates healing of oral ulcer by regulating EGF levels. This finding provides a new approach to the treatment of oral ulcers.
\end{abstract}

Keywords: Oral ulcer, Dexamethasone, Inflammatory factors, Epidermal growth factors

\begin{abstract}
This is an Open Access article that uses a fund-ing model which does not charge readers or their institutions for access and distributed under the terms of the Creative Commons Attribution License (http://creativecommons.org/licenses/by/4.0) and the Budapest Open Access Initiative (http://www.budapestopenaccessinitiative.org/read), which permit unrestricted use, distribution, and reproduction in any medium, provided the original work is properly credited.
\end{abstract}

Tropical Journal of Pharmaceutical Research is indexed by Science Citation Index (SciSearch), Scopus, International Pharmaceutical Abstract, Chemical Abstracts, Embase, Index Copernicus, EBSCO, African Index Medicus, JournalSeek, Journal Citation Reports/Science Edition, Directory of Open Access Journals (DOAJ), African Journal Online, Bioline International, Open-J-Gate and Pharmacy Abstracts

\section{INTRODUCTION}

Oral ulcers are superficial lesions which vary in size and shape from round to oval. They often occur on the lips, cheeks and tongue edges, usually accompanied by congestion and local pain. It is known that severe oral mucosal pain, unbearable burning pain and long-term recurrent risks associated with oral ulcers directly affect the immunity of the patients, leading to metabolic 
disorders, halitosis, chronic pharyngitis and constipation [1,2]. The incidence of oral ulcers has gradually increased as a result of lifestyle modifications. Oral ulcers may lead to low immunity, and low immunity enhances the occurrence of recurrence of oral ulcers. Such repeated attacks of oral ulcers may form a vicious circle which seriously affects the productivity and life of the patients [3,4]. At present, the treatment of oral ulcers is based mainly on drugs, and different drug treatments produce different effects $[5,6]$. One of these drugs is dexamethasone, an adrenocortical hormone drug which exerts anti-inflammatory, anti-fever, anti-allergic and immunosuppressive effects [7]. Studies have shown that dexamethasone is useful in the treatment of oral ulcers [8]. However, the mechanisms involved in the healing process have not yet been elucidated. The present study was carried out to investigate the effect of dexamethasone on the symptoms of oral ulcer, and the levels of EGF, MDA, IL-6, IL-8, and TNF- $\alpha$ in rabbits with oral ulcer. This was with a view to providing a basis for the clinical use of dexamethasone in the treatment of oral ulcers.

\section{EXPERIMENTAL}

\section{Animals}

Forty SPF New Zealand rabbits (20 males and 20 females) weighing 2900 - 3400 g, were purchased from Xi'an Jiaotong University Medical Laboratory Animal Center. All protocols used in the animal experiments were approved by the Ethics Committee on Animal Research at Xi'an Jiaotong University (approval ref. no: XAUML- 20190271A). The animal experiments were performed in accordance with the guidelines of the Committee on the Care and Use of Laboratory Animals [9]. The rabbits were fed with pellet feed. Adequate drinking water was supplied during the experiment. Room temperature was kept at $20 \pm 2{ }^{\circ} \mathrm{C}$, and mean relative humidity was kept 40 - $60 \%$. Four rabbits were randomly selected for use in establishment of an oral ulcer model (model group) by applying $40 \%$ glacial acetic acid to the buccal membranes of the animals. The other animals were randomly divided into three groups: normal control group (group A), normal saline (NS) pellicles group (group B), in which the oral ulcer model was established but the animals were treated with NS pellicles; and dexamethasone group (group $\mathrm{C}$ ), in which the oral ulcer animals were treated with dexamethasone. There were 12 animals in each group (6 males and 6 females).

\section{Drugs and reagents}

Hydroxypropyl methylcellulose was purchased from Gomez Chemicals China Ltd. Dexamethasone tablets were bought from Guangdong Huanan Pharmaceutical Co. Ltd. Reverse transcription kit was provided by Beijing Norbold Technology Co. Ltd, while RNA extraction kit was brought from Beijing Solelab Technology Co. Ltd. Taq PCR Master Mix x2 was purchased from Beijing Biotek Biotech Co. Ltd., while DNA Master was provided by Beijing Tianwei Times.

\section{Equipment}

Tissue homogenizer was purchased from Shanghai Jinuo Electronics Co. Ltd. Automatic dyeing machine was provided by Shenzhen Yongnian Technology Co. Ltd., while pathology slicing microtome was purchased from Fuguang Precision Instrument (China) Co. Ltd, while UV gel imaging analysis system was provided by Nanjing Shiyan Technology Co. Ltd. Color medical graphic analysis system was obtained from Wuhan Qianping Imaging Technology Co. Ltd., while UV spectrophotometer was purchased from Thermo Fisher Scientific Co. Ltd.

\section{Preparation of drug}

Dexamethasone tablets (600 g), Tween-70 (5.0 $\mathrm{mL}$ ) and glycerol $(20.0 \mathrm{~mL})$ were dissolved in saturated solution of hydroxypropyl methylcellulose solution, and the volume was made up to $1000 \mathrm{~mL}$. The solution was fully stirred to form gel-like consistency. Then, the final solution was allowed to stand for $24 \mathrm{~h}$ and spread evenly to dry. On drying, the sample was cut into several films of diameter of $1 \mathrm{~cm}$. The films were disinfected with ultraviolet radiation and sealed with polyethylene film.

Saline control was made by dissolving refined $\mathrm{NaCl}$ (salt, $9 \mathrm{~g}$ ) in saturated hydroxypropyl methylcellulose solution to a total volume of 1000 $\mathrm{mL}$. The saline solution was subjected to the same drug preparation methods used for dexamethasone.

\section{Establishment of oral ulcer model}

The rabbits were anesthetized with $3 \%$ sodium pentobarbital at an injection dose of $30 \mathrm{mg} / \mathrm{kg}$ ). Then, $40 \%$ glacial acetic acid was administered into the buccal membrane for $60 \mathrm{sec}$ using a glass rod of diameter of $7 \mathrm{~mm}$ and length $10 \mathrm{~cm}$. Then, the cauterization parts were rinsed for 1 min to form a white lesion with a diameter of 7 $\mathrm{mm}$. Congestion and red swelling were observed 
in the pars buccalis, $24 \mathrm{~h}$ later. Yellow or white pseudo membrane covered the treated parts, indicating that the oral ulcer model was successfully established.

\section{Drug administration}

All drugs were applied after the model was established. No treatments were carried out in group $A$ and the model group. The oral ulcer in rabbits in group $B$ were treated with saline pellicles, while dexamethasone pellicles were used to treat oral ulcer in rabbits in group $\mathrm{C}$. The pellicles were attached twice a day (at 9:00 and 17:00), for 7 days, with one film on each side for 5 min. After each application of the drug, the treated parts were rinsed with warm normal saline.

\section{Determination of treatment effects}

The symptoms and signs presented by the rabbits were visually observed. These involved changes in liveness, body weight, feces and urine, fur color, and feeding habits.

\section{Morphological changes and measurement of ulcer areas}

The rabbits used for ulcer model identification were sacrificed on the day that the models were successfully established (0 day). Thereafter, 4 rabbits in groups $A, B$ and $C$ were randomly chosen according to the random number table, and sacrificed using euthanasia on the $2^{\text {nd }}, 4^{\text {th }}$ and $7^{\text {th }}$ days of drug administration. Morphological features of the oral ulcer such as hyperemia, color of oral mucosal, and presence of pseudo-membrane covering, were recorded. The oral cavity of each sacrificed rabbit was fully exposed, and the oral mucosal tissue was taken at the junction of ulcer and normal mucosa, for histological studies [3]. The ulcer size was measured with a vernier caliper, and the ulcer area was calculated with Image Converter software.

\section{Determination of EGF levels in rabbit oral mucosa}

The right side of the pathological specimens of the ulcer samples were fixed in $10 \%$ formaldehyde solution and embedded in paraffin. However, the left side was quickly frozen in liquid nitrogen to prevent mRNA degradation, after which the tissues were stored in a $-70{ }^{\circ} \mathrm{C}$ refrigerator prior to use. The mRNA expression level of EGF was determined using RT-PCR assay kit in line with the instructions of the kit manufacturer. Quantity software was applied for calculating the ratios of optical density values obtained from the bands of the RT-PCR products, relative to $\beta$-actin standard.

Determination of levels of MDA, IL-6, IL-8 and TNF- $\alpha$, and hematoxylin-eosin (H \& E) staining

Enzyme-linked immunosorbent assay (ELISA) kits were used to determine the contents of MDA, IL-6, IL-8, and TNF- $\alpha$ in tissue homogenates of oral ulcer samples according to instructions of the respective kit manufacturers. Another part of ulcerous tissue was routinely processed for light microscopy using $\mathrm{H}$ \& $\mathrm{E}$ staining. Pathological changes in the ulcer tissues in each animal were examined under a light microscope and photographed.

\section{Statistical analysis}

The SPSS 21.0 software was used for statistical analysis. Data are expressed as mean \pm SD. Student's $t$-test was used for analysis of differences between two groups, while one-way ANOVA and Duncan test were used for multigroup comparisons. Differences were assumed significant at $p<0.05$.

\section{RESULTS}

\section{Symptoms and signs observed in the rabbits}

Rabbits in group A had normal dry lips, normal liveliness, flexible responses, good appetite, smooth shiny fur, as well as light-yellow urine, and normal defecation prior to model establishment. However, after establishment of the oral ulcer model, the rabbit lips became wet, with occasional drooling. The physical activities of the animals decreased, and they appeared depressed, leading to decreased intake of feed and water, and weight loss. The hair color was lighter and rougher than before; the yellow urine output was decreased (oliguria), and the frequency of defecation was decreased. The rabbits in group $\mathrm{C}$ treated with dexamethasone recovered gradually, with increases in feed intake, water intake and body weight. Besides, their lips were drier than before, their hair color gradually became smooth, their liveliness gradually increased, and their defecation and urination become normal. The recovery rate in Group B was much slower than that in Group C.

\section{Morphology of ulcer and ulcer areas in rabbits in groups $B$ and $C$}

The oral mucosa was light, reddish and shiny in group A. After exposure to glacial acetic acid for 
$24 \mathrm{~h}$, round or oval ulcers with diameters of about $7 \mathrm{~mm}$ were formed on the oral cheeks of the rabbits. The edges of the ulcer were neat, with red swelling and congestion surrounding the ulcer areas, the surfaces of which were covered with yellow or gray pseudo membranes. With time, the congestion and edema in the oral mucosa were gradually mitigated, and luster was gradually recovered. The recovery conditions in group $\mathrm{C}$ were better than those in group $\mathrm{B}$. The ulcer areas in Group C were significantly smaller than those in group $B$ on the $2^{\text {nd }}, 4^{\text {th }}$ and $7^{\text {th }}$ days after drug administration $(p<0.05)$. These results are shown in Table 1.

Table 1: Ulcer areas at different time points in groups $\mathrm{B}$ and $\mathrm{C}\left(\mathrm{mm}^{2}\right)$

\begin{tabular}{lll}
\hline Time point & Group B & Group C \\
\hline $2^{\text {nd }}$ day of treatment & $46.43 \pm 2.68$ & $30.2 \pm 2.51^{\#}$ \\
\hline $4^{\text {th }}$ day of treatment & $35.14 \pm 1.95$ & $26.91 \pm 0.76^{\#}$ \\
\hline $7^{\text {th }}$ day of treatment & $26.55 \pm 2.14$ & $15.86 \pm 1.42^{\#}$ \\
\hline $\begin{array}{l}\text { Data are presented as mean } \pm \text { SD. \#P }<0.05, \\
\text { compared with group B }\end{array}$
\end{tabular}

\section{EGF levels in the buccal mucosal tissue in each group}

As shown in Figures 1 and 2, the mRNA expression of EGF in groups $B$ and $C$ were significantly increased gradually on the $2^{\text {nd }}, 4^{\text {th }}$ and $7^{\text {th }}$ days of drug administration $(p<0.05)$.

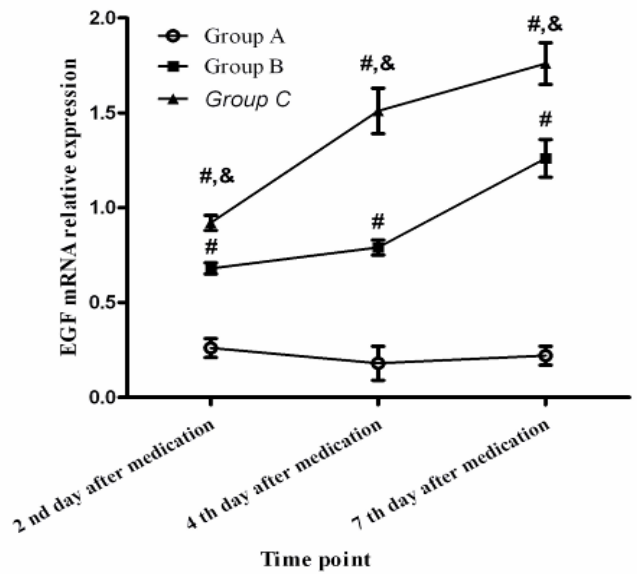

Figure 1: EGF mRNA expression levels in the buccal mucosal tissues in all groups. ${ }^{\#} P<0.05$, compared with group $A ;{ }^{\&} p<0.05$, compared with group $B$.

\section{Levels of MDA, and expression levels of IL-6, IL-8, TNF- $\alpha$ in rabbit tissues}

The levels of MDA, IL-6, IL-8, and TNF- $\alpha$ in ulcer samples in group $B$ were higher than the corresponding levels in group A $(p<0.05)$. Moreover, the levels of MDA, IL-6, IL-8, and TNF- $\alpha$ in group $C$ were significantly higher than the corresponding levels in group B $(p<0.05)$. These results are presented in Figure 3.

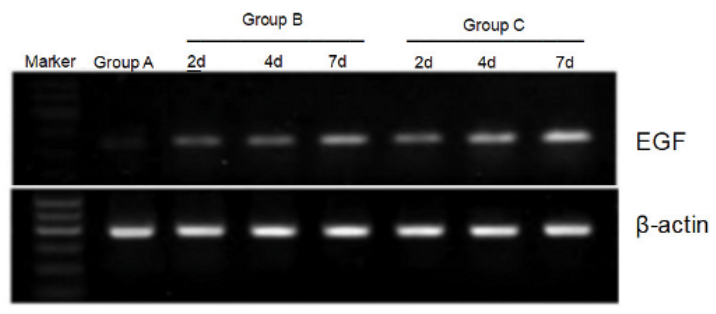

Figure 2: Expression of EGF mRNA in oral mucosa
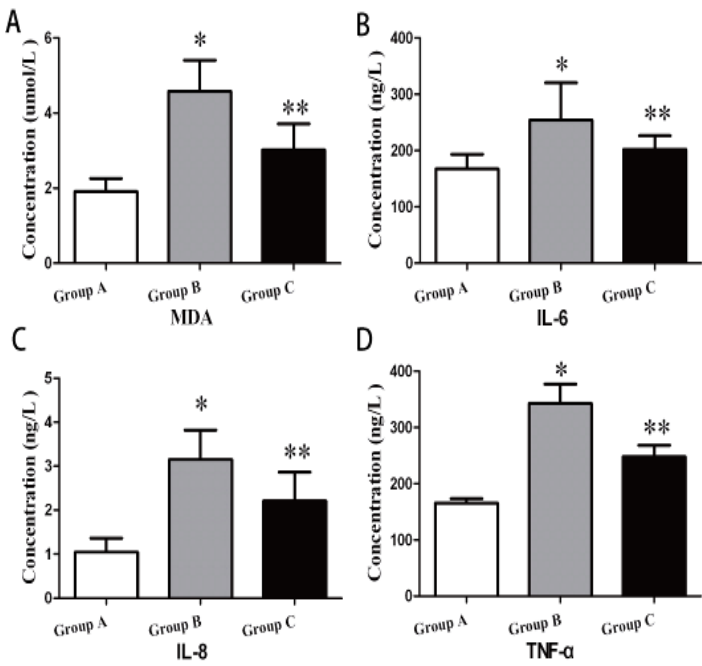

Figure 3: MDA and expression levels of IL-6, IL-8 and TNF- $\alpha$ in the 3 groups. ${ }^{*} P<0.05$, group $B$ vs group $C$; ${ }^{* *} p<0.05$, group $C$ vs group $B$

\section{Pathological changes in rabbit buccal mucosa}

The nucleus was blue and the cytoplasm was light red after $\mathrm{H} \& \mathrm{E}$ staining. In group $\mathrm{A}$, the oral mucosal epithelium was completely covered and the underlying layer was lamina propria which was composed of connective tissues. Besides, no obvious inflammatory cell infiltration was observedln groups $B$ and $C$, the mucosal epithelial cells were necrotic and detached after 2 days of treatment. There were more inflammatory cells and almost no new fibroblasts in group B. Moreover, the population of inflammatory cells was significantly reduced, with only a few new fibroblasts present. However, after 4 days of treatment, the number of inflammatory cells in group B began to decrease, while the number of inflammatory cells in group $C$ decreased continuously, and many new 
fibroblasts were detected. After 7 days of dexamethasone treatment, the number of inflammatory cells in group B was significantly reduced, and many new fibroblasts appeared. The ulcer surface in group $\mathrm{C}$ was almost completely covered by mucosal epithelium, and the ulcer appeared to be healed (Figure 4).

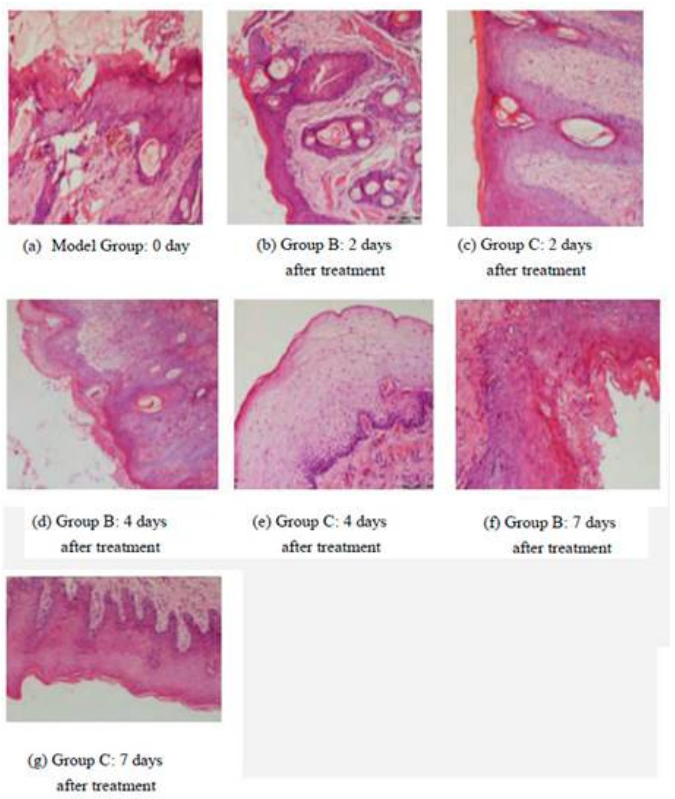

Figure 4: Photomicrographs of buccal mucosa sections in each group $(\mathrm{H} \& \mathrm{E} ; \times 200)$

\section{DISCUSSION}

Oral ulcer is a buccal mucosa disease which is frequently seen in clinics. It is well known that oral ulcer easily occurs repeatedly. Recurrent aphthous ulcers occurs periodically, often on the tongue, buccal mucosa, and inside the lips $[10,11]$.

The pathogenesis of oral ulcers has not been fully understood. However, the potential predisposing factors include genetic, viral and bacterial infections, food allergies, deficiency of vitamins or trace elements, systemic diseases (celiac disease, Crohn's disease, ulcerative colitis, and AIDS); accentuated oxidative stress responses, local trauma, stress and endocrine disorders [12,13]. Histological examination of the lesion areas in oral ulcer tissue revealed a high degree of leukocyte infiltration. Epithelial fistula was formed because of intracellular and intercellular edemas due to dense infiltration of lymphocytes and monocytes. The pathological changes induce infiltration of polymorphonuclear leukocytes and plasma cells, leading to detachment of epithelial tissues, which in turn results in ulcer formation [14]. At present, no treatments for oral ulcers are available. Local treatments are used mainly to reduce the inflammatory responses, relieve the pain and prevent infection. There is need for systemic therapy, especially for patients whose conditions are severe [15].

Dexamethasone is a glucocorticoid which has anti-inflammatory, anti-endotoxin, and immunosuppressive effects. It reduces exudation of inflammatory substances, mitigates tissue edema, and reduces the synthesis and release of inflammatory chemicals (for example, histamine) by reducing the permeability of cells and capillaries, enhancing local metabolism and accelerating the healing of ulcers [16]. Studies have shown the potential beneficial effect of combination of $\mathrm{Xi}$ lei powder, Sanqi powder and dexamethasone in the treatment of oral ulcers [17]. This combination therapy exerts antiinflammatory, analgesic, heat-clearing and detoxifying effects, as well as removal of necrotic tissues and promotion of granulation. Besides, it regulates the immune system and restores normal immune functions. As a result, this combination therapy achieves excellent clinical effects on oral ulcers. Another study has also demonstrated the specificity of dexamethasone acetate tablets in the treatment of recurrent oral ulcers [18]. This indicates that dexamethasone can be used in the treatment of recurrent oral ulcers. It has been reported that dexamethasone effectively reduced symptoms of oral ulcers in rabbits, relieved inflammatory reactions of local tissues, reduced exudation of tissue fluids, and promoted rapid recovery from ulcers, thereby shortening their duration. Epidermal growth factor (EGF) induces cell growth and proliferation. Studies have shown that EGF plays an important role in the protective barrier of oral mucosa, and provides a basis for the growth, differentiation and proliferation of oral mucosal epithelial cells, especially mucosal basal cells. Patients with oral ulcers often have low levels of EGF. This delays the healing of oral ulcers.

The results of this study showed that there were significant differences in the mRNA expression levels of EGF between group $B$ and group $C$ on the $2^{\text {nd }}, 4^{\text {th }}$ and $7^{\text {th }}$ days of drug administration, suggesting that dexamethasone enhances the expression of EGF mRNA in oral mucosa and increases the secretion of EGF. The expression of EGF mRNA was increased gradually with time, suggesting that EGF is involved in the healing process of oral ulcer. Studies have shown that the reduction of EGF secretion in the oral mucosa of the patients with ulcer hinders recovery from the disease [20]. Therefore, dexamethasone improves the self-repair ability of 
oral ulcers by promoting the secretion of EGF in the oral mucosa, thereby enhancing the healing of ulcers.

\section{Limitation of the study}

One major limitation in this study is that in vitro assays on cell lines were not used to confirm the in vivo results.

\section{CONCLUSION}

Dexamethasone enhances the self-repair ability of oral ulcers by promoting the secretion of EGF in the oral mucosa. This finding provides a new insight into the treatment of oral ulcers.

\section{DECLARATIONS}

\section{Conflict of interest}

No conflict of interest is associated with this work.

\section{Contribution of authors}

We declare that this work was done by the authors listed in this manuscript, and all liabilities pertaining to claims relating to the content of this article will be borne by the authors. All authors read and approved the manuscript for publication. Weiliang $\mathrm{Wu}$, Wei Cheng and Daxu Li conceived and designed the study. Le Ren, Hong Tao, Zhe Zhang, Chunni Deng, Wei Cheng and Rui Wang collected and analyzed the data, while Weiliang Wu and Jianyong Ruan wrote the manuscript. Weiliang $\mathrm{Wu}$ and Jianyong Ruan contributed equally to this work.

\section{Open Access}

This is an Open Access article that uses a funding model which does not charge readers or their institutions for access and distributed under the terms of the Creative Commons Attribution License (http://creativecommons.org/licenses/by/ 4.0) and the Budapest Open Access Initiative (http://www.budapestopenaccessinitiative.org/rea d), which permit unrestricted use, distribution, and reproduction in any medium, provided the original work is properly credited.

\section{REFERENCES}

1. Santarelli A, Mascitti M, Galeazzi R, Marziali A, Busco F, Procaccini M. Oral ulcer by Sphingomonas paucimobilis: first report. Int J Oral Maxillofac Surg 2016; 45(10): 1280-1282.
2. Dubrocq G, Needles M, Jantausch B. Recurrent Fever and Mouth Ulcers in a Healthy Child. J Pediatric Infect Dis Soc 2017; 6(3): e155-e157.

3. Ramírez-Amador VA, Espinosa E, González-Ramírez I, Anaya-Saavedra G, Ormsby CE, Reyes-Terán G. Identification of oral candidosis, hairy leukoplakia and recurrent oral ulcers as distinct cases of immune reconstitution inflammatory syndrome. Int J STD AIDS 2009; 20(4): 259-261.

4. ZhanHai, YuChe, Jin MaXin, He JianMin. Effect of Aloe vera polysaccharides on immunity and antioxidant activities in oral ulcer animal models. Carb Poly 2009; 75(2): 307-311.

5. Barrons RW. Treatment strategies for recurrent oral aphthous ulcers. Am J Health Sys Pharm 2001; 58(1): 41-53.

6. Lim YS, Kwon SK, Park JH, Cho CG, Park SW, Kim WK. Enhanced mucosal healing with curcumin in animal oral ulcer model. Laryngoscope 2016; 126(2): E68-E73.

7. Alamoudi NM, El Ashiry EA, Farsi NM, El Derwi DA, Atta HM. Treatment of oral ulcers in dogs using adipose tissue-derived mesenchymal stem cells. J Clin Pediatr Dent 2014; 38(3): 215-222.

8. Schürkämper $M$, Medele R, Zausinger S, SchmidElsaesser R, Steiger HJ. Dexamethasone in the treatment of subarachnoid hemorrhage revisited: a comparative analysis of the effect of the total dose on complications and outcome. J Clin Neurosci 2004; 11(1): 20-24.

9. National Research Council (US) Committee for the Update of the Guide for the Care and Use of Laboratory Animals. Guide for the Care and Use of Laboratory Animals.8th edition. Washington (DC): National Academies Press (US); 2011.

10. Patten SF, Tomecki KJ. Wegener's granulomatosis: cutaneous and oral mucosal disease. I Am Acad Dermatol 1993; 28(5 Pt 1): 710-718.

11. Leão JC, Gomes VB, Porter S. Ulcerative lesions of the mouth: an update for the general medical practitioner. Clinics (Sao Paulo) 2007; 62(6): 769-780.

12. Han J, He Z, Li K, Hou L. Microarray analysis of potential genes in the pathogenesis of recurrent oral ulcer. Int $\mathrm{J}$ Clin Exp Pathol 2015; 8(10): 12419-12427.

13. Birek C, Grandhi R, McNeill K, Singer D, Ficarra G, Bowden G. Detection of Helicobacter pylori in oral aphthous ulcers. J Oral Pathol Med 1999; 28(5): 197203.

14. Loots MA, Lamme EN, Zeegelaar J, Mekkes JR, Bos JD, Middelkoop E. Differences in cellular infiltrate and extracellular matrix of chronic diabetic and venous ulcers versus acute wounds. J Invest Dermatol 1998; 111(5): 850-857.

15. Karacayli U, Mumcu G, Simsek I, et al. The close association between dental and periodontal treatments and oral ulcer course in behcet's disease: a prospective clinical study. J Oral Pathol Med 2009; 38(5): 410-415.

16. Funato $H$, Kobayashi $A$, Watanabe $Y$. Differential effects of antidepressants on dexamethasone-induced nuclear

Trop J Pharm Res, February 2021; 20(2): 356 
translocation and expression of glucocorticoid receptor. Brain Res 2006; 1117(1): 125-134.

17. Farshi FS, Ozer AY, Ercan MT, Hincal AA. In-vivo studies in the treatment of oral ulcers with liposomal dexamethasone sodium phosphate. J Microencapsul. 1996; 13(5): 537-544.

18. Wang $Q Q$, Chen HL, Zong F, Huang HM, Zang MS. Observation of the clinical efficacy of treating recurrent oral ulcer with He-Ne laser and acupoint-injection. Laser J 2008; 29(3):80-81.
19. Maynard AA, Dvorak K, Khailova L, Dobrenen $H$, Arganbright KM, Halpern MD, Kurundkar $A R$, Maheshwari A, Dvorak B. Epidermal growth factor reduces autophagy in intestinal epithelium and in the rat model of necrotizing enterocolitis. Am J Physiol Gastrointest Liver Physiol 2010; 299(3): G614-G622.

20. Konturek SJ, Brzozowski T, Dembinski A, Warzecha A, Drozdowicz D. Comparison of solcoseryl and epidermal growth factors (EGF) in healing of chronic gastroduodenal ulcerations and mucosal growth in rats. Hepatogastroenterol 1988; 35(1): 25-29. 